\title{
Como trabalhar com "raça" em sociologia"
}

Antonio Sérgio Alfredo Guimarães

Universidade de São Paulo

Correspondência:

Antonio Sérgio Alfredo Guimarães

Departamento de Sociologia - USP

Av. Luciano Gualberto, 315 - Cid.

Universitária

05508-900 - São Paulo - SP

e-mail: asguima@usp.br

\section{Resumo}

Numa exposição didática, de caráter teórico-metodológico, o autor explica o modo como utiliza em suas pesquisas a categoria "raça", em conexão com outras categorias como "cor", "etnia", "região", "classe", "nação", "povo", "estado", etc.

A partir do pressuposto de que os conceitos, teóricos ou não, só podem ser aplicados e entendidos no seu contexto discursivo, 0 autor estabelece a distinção entre conceitos "analíticos" e "nativos", ou seja, entre categorias retiradas de um corpus teórico e categorias que compõem o próprio universo discursivo dos sujeitos que estão sendo analisados, mas que devem ser utilizados pelo sociólogo.

$\mathrm{Na}$ parte central do texto, o autor esboça uma história dos significados da categoria "raça" no Brasil e das diversas explicações do caráter das relações entre brancos e negros avançadas pela Sociologia: desde o trabalho pioneiro de Donald Pierson, nos anos 1940, passando pelos estudos da Unesco, nos anos 1950, os trabalhos da chamada "escola paulista", nos anos 1960, e a retomada da teoria da "democracia racial" nos anos mais recentes, em estreito diálogo com os movimentos negros.

0 autor termina por fazer uma pequena discussão sobre os diversos estímulos, ou perguntas, dados em pesquisas tipo survey, para definição e mensuração da variável cor ou raça.

\section{Palavras - chave \\ Raça - Etnia - Classe - Nação.}

1. Este texto reproduz, de maneira ligeiramente modificada, uma aula que proferi, em abril de 2000 , a pedido de Nadya Araújo Guimarães, em seu seminário de orientação de bolsistas, na USP. Mais tarde, esse texto foi modificado e apresentado no ciclo de seminários do projeto "Gestão local, empregabilidade e eqüidade de gênero e raça: uma experiência de política pública na região do $A B C$ paulista", em desenvolvimento no CEBRAP, em 2001. 


\title{
How to work with "race" in sociology"
}

\author{
Antonio Sérgio Alfredo Guimarães
}

Universidade de São Paulo

Contact:

Antonio Sérgio Alfredo Guimarães Departamento de Sociologia - USP Av. Luciano Gualberto, 315 - Cid. Universitária

05508-900 - São Paulo - SP

e-mail: asguima@usp.br

1. This text reproduces in a slightly modified form, a lecture that I gave in April 2000 by invitation of Nadya Araújo Guimarães at her student supervision seminar at USP. That text was later altered and presented in 2001 at the series of seminars within the project "Local management, employability, and gender and race equity: an experience of public policy in the São Paulo ABC area" in course at CEBRAP.

\section{Abstract}

In a didactic account of a theoretical-methodological nature the author explains how the category of "race" is used in his research, in connection with other categories such as "color", "ethnics", "class", "nation", "people", "state", etc.

Assuming that concepts, theoretical or otherwise, can only be applied and understood within their discursive contexts, the author establishes the distinction between "analytical" and "native" concepts, that is, between categories extracted from a theoretical corpus, and those that comprise the discursive universe of the subjects being analyzed, but that must be employed by the sociologist.

In the central part of the text, the author sketches a history of the meanings of the category "race" in Brazil and of the various explanations of the nature of the relations between white and black people put forward by Sociology: starting with the 1940s pioneering work of Donald Pierson, going through the UNESCO studies of the 1950s and the work of the so-called "São Paulo School" in the 1960s, up to the more recent revival of the theory of "racial democracy" in close dialogue with Black movements. The author concludes the article with a brief discussion about the various questions or stimuli given in surveys for the definition and measurement of the color or race variable.

\section{Keywords}

Race - Ethnics - Class - Nation. 
Neste texto, pretendo fazer uma discussão conceitual sobre "raça" que seja também metodológica. Gostaria de lembrar, antes de tudo, que se trata de uma exposição sobre 0 modo como eu trabalho conceitualmente. Posso parecer categórico demais, às vezes, mas se trata apenas de uma interpretação minha, pois nada do que eu falo forma um corpo dogmático estabelecido ou cientifico; é apenas a explicitação crítica da maneira como eu trabalho.

Vamos começar pelos conceitos. Fazemos sempre uma distinção, nas ciências sociais, entre dois tipos de conceitos: os analíticos, de um lado, e os que podemos chamar de "nativos"; ou seja, trabalhamos com categorias analíticas ou categorias nativas. Um conceito ou categoria analítica é o que permite a análise de um determinado conjunto de fenômenos, e faz sentido apenas no corpo de uma teoria. Quando falamos de conceito nativo, ao contrário, é porque estamos trabalhando com uma categoria que tem sentido no mundo prático, efetivo. Ou seja, possui um sentido histórico, um sentido específico para um determinado grupo humano. A verdade é que qualquer conceito, seja analítico, seja nativo, só faz sentido no contexto ou de uma teoria específica ou de um momento histórico específico. Acredito que não existem conceitos que valham sempre em todo lugar, fora do tempo, do espaço e das teorias. São pouquíssimos os conceitos que atravessam o tempo ou as teorias com 0 mesmo sentido. Se é assim, os termos de que estamos falando são termos que devem ser compreendidos dentro de certos contextos. Gostaria, portanto, de frisar esse aspecto. Observação que pode parecer bem simples, mas que trata de uma regra necessária para evitar confusões sobre o que vem a seguir.

0 que é raça? Depende. Realmente depende de se estamos falando em termos científicos ou de se estamos falando de uma categoria do mundo real. Essa palavra "raça" tem pelo menos dois sentidos analíticos: um reivindicado pela biologia genética e outro pela sociologia. Quando digo isso, estou querendo também provocar alguns antropólogos em flor, como diria meu velho professor Vivaldo da Costa Lima (1971), que chegam a ter arrepios ao ouvir que "raça" pode ser um conceito sociológico; o que consideram um absurdo. Ademais desses usos analíticos, temos "raça" como conceito nativo. Vamos destrinchar isso um pouco mais.

Vamos voltar, por um momento, ao final do século XIX para lembrar que quando a sociologia se forma - lemos isso em Marx (1974), em Durkheim (1970), em Boas (1940) - ocorre um deslocamento em termos de explananda: abandonamos as explicações sobre o mundo social baseadas em raça ou clima, em favor de explicações baseadas no social e na cultura. 0 que funda as ciências sociais é essa idéia de cultura. Que idéia é essa? É a idéia de que a vida humana, a sociedade política, etc. não são determinadas, de uma maneira forte, por nada além da própria vida social. Quem não se lembra de Durkheim repetindo: "um fato social só pode ser explicado por outro fato social"? Essa mesma idéia vai ser desenvolvida por Boas e por outros. Podemos pensar em cultura material ou simbólica, e essa idéia de cultura simbólica é muito importante para nós que trabalhamos com "raça". Construímos o sentido de nossa vida social e individual, assim como construímos também os artefatos que nos permitem sobreviver e reproduzir de maneira ampliada a nossa vida em sociedade. Aquilo que chamamos de natureza física pode ser considerado, de agora em diante, como simples condicionante da vida social. Lembremos Weber (1970) - cuja leitura é essencial: a ação social só existe como tal quando a ela se cola um sentido subjetivo. Assim se constituiu o campo das ciências sociais.

Mas sabemos também que o termo "raça" não desapareceu totalmente do discurso científico. Não apenas do discurso da biologia, mas também de todos os discursos que insistem em explicar a vida social em concorrência com a sociologia. A biologia e a antropologia física criaram a idéia de raças humanas, ou seja, a idéia 
de que a espécie humana poderia ser dividida em subespécies, tal como o mundo animal, e de que tal divisão estaria associada ao desenvolvimento diferencial de valores morais, de dotes psíquicos e intelectuais entre os seres humanos. Para ser sincero, isso foi ciência por certo tempo e só depois virou pseudociência. Todos sabemos que o que chamamos de racismo não existiria sem essa idéia que divide os seres humanos em raças, em subespécies, cada qual com suas qualidades. Foi ela que hierarquizou as sociedades e populações humanas e fundamentou um certo racismo doutrinário. Essa doutrina sobreviveu à criação das ciências sociais, das ciências da cultura e dos significados, respaldando posturas políticas insanas, de efeitos desastrosos, como genocídios e holocaustos. Depois da tragédia da Segunda Guerra, assistimos a um esforço de todos os cientistas - biólogos, sociólogos, antropólogos para sepultar a idéia de raça, desautorizando 0 seu uso como categoria científica. 0 desejo de todos era apagar tal idéia da face da terra, como primeiro passo para acabar com o racismo. Alguns cientistas naturais, biólogos, tentaram impedir o uso do conceito na biologia, mesmo que tenha ficado claro que ele não pretendia mais explicar a vida social e as diferenças entre os seres humanos; propuseram que o seu nome fosse mudado, que se passasse a falar de "população" para se referir a grupos razoavelmente isolados, endogâmicos, que concentrassem em si alguns traços genéticos. Essa idéia de "população", apesar de próxima de "raça", seria extremamente útil em alguns estudos biológicos e, ao mesmo tempo, evitaria as implicações psicológicas, morais e intelectuais do antigo termo. Mesmo que se possa demonstrar estatisticamente que a população mundial, em termos genéticos, não pode ser dividida em raças, seria necessário, para alguns biólogos, conservar a idéia da existência desses grupamentos geneticamente mais uniformes.

O que significa a não existência de raças humanas para a biologia? Significa que as diferenças internas, digamos aquelas relativas às populações africanas, maiores do que as diferenças externas, aquelas existentes entre populações africanas e populações européias, por exemplo. Ou seja, é impossível definir geneticamente raças humanas que correspondam às fronteiras edificadas pela noção vulgar, nativa, de raça. Dito ainda de outra maneira: a construção baseada em traços fisionômicos, de fenótipo ou de genótipo, é algo que não tem o menor respaldo científico. ${ }^{2}$

Ou seja, as raças são, cientificamente, uma construção social e devem ser estudadas por um ramo próprio da sociologia ou das ciências sociais, que trata das identidades sociais. Estamos, assim, no campo da cultura, e da cultura simbólica. Podemos dizer que as "raças" são efeitos de discursos; fazem parte desses discursos sobre origem (Wade 1997). As sociedades humanas constroem discursos sobre suas origens e sobre a transmissão de essências entre gerações. Esse é o terreno próprio às identidades sociais e o seu estudo trata desses discursos sobre origem. Usando essa idéia, podemos dizer o seguinte: certos discursos falam de essências que são basicamente traços fisionômicos e qualidades morais e intelectuais; só nesse campo a idéia de raça faz sentido. 0 que são raças para a sociologia, portanto? São discursos sobre as origens de um grupo, que usam termos que remetem à transmissão de traços fisionômicos, qualidades morais, intelectuais, psicológicas, etc., pelo sangue (conceito fundamental para entender raças e certas essências). Existem vários outros tipos de discursos que são também discursos sobre lugares: lugares geográficos de origem - "a minha Bahia, o meu Amazonas, a minha Itália" -, aquele lugar de onde se veio e que permite a nossa identificação com um grupo enorme de pessoas. Quando falamos de lugares, falamos de etnias. Outras vezes, os discursos sobre origens são discursos sobre 0 modo de fazer certas coisas (por exemplo: "nós fazemos desse jeito, nós comemos um alimento cortando-o na diagonal e não na vertical, como

2 . Uma boa discussão deste ponto pode ser encontrada em Appiah (1997). 
fazem os bárbaros"); esses são discursos que podem também formar uma comunidade. ${ }^{3}$ É muito importante observarmos a distinção de Tönnies, retomada por Weber (1970), entre "associação" e "comunidade". São dois conceitos fundamentais. Lembrando sempre que estamos falando de discursos que criam comunidades, não associações. 0 que é uma associação? Associação é simplesmente uma reunião de pessoas ligadas por certos interesses, interesses que podem ser submetidos à crítica. Um sindicato é certamente uma associação, formado a partir de uma mesma situação de classe, de uma posição comum num mercado de bens e serviços. Não estamos falando, portanto, de comunidades, como acontece quando estamos nos referindo a etnias ou raças. Estas últimas podem mesmo se transformar numa outra coisa, a qual devemos designar por um outro nome, como quando passam a reivindicar, não apenas uma origem comum, mas um certo destino político, também comum. Quando etnias ou raças passam a reivindicar um destino político comum, quando formam uma comunidade de origem e de destino, então estamos em presença de uma nação. É perfeitamente plausível dizermos, por exemplo, que os negros americanos, que têm a raça como categoria nativa se transformaram, em algum momento, em uma nação, formando um movimento nacionalista.

Um parêntese: quando se fala em raça, nos Estados Unidos, isso faz imediatamente sentido para as pessoas; não se pode viver nos Estados Unidos sem ter uma raça, mesmo que se tenha que inventar uma denominação como latino - que designa uma uniformidade cultural e biológica de outro modo inexistente, mas imprescindível para possibilitar o diálogo com pessoas que se designam "negras", "brancas", "judias", etc. Todos os grupos étnicos viram raça nos Estados Unidos, porque raça é um conceito nativo classificatório, central para a sociedade americana. Por outro lado, quando nos referimos ao afrocentrismo americano, ao panafricanismo, ao islamismo de Faraken, nitidamente estamos tratando de movimentos que estão reivindicando, não somente uma origem comum, mas um destino político comum enquanto povo.

Aliás, a noção de "povo" é também muito importante. 0 povo é justamente o sujeito dessa comunidade imaginária de origem ou de destino, o conjunto das pessoas da comunidade: o povo de santo, o povo brasileiro, 0 povo baiano, o povo paulista. Nenhum povo existe sem a comunidade que lhe oferece uma origem ou um destino: o candomblé, o Brasil, a Bahia, São Paulo.

A distinção clássica de Weber (1970) entre Estado e Nação é bastante conhecida. Aliás, um outro parêntese: este texto está parecendo uma aula de sociologia, não é? Mas eu trabalho assim mesmo, fazendo distinções analíticas que só fazem sentido quando empregadas para entender um fato concreto. Em certos momentos do meu raciocínio é como se estivéssemos no mundo da lua, pois me refiro a uma distinção puramente analítica, em abstrato, quando tudo 0 que existe é uma realidade concreta, singular. Os conceitos só fazem sentido num mundo teórico determinado, não faz sentido sair daqui para aplicar ali este discurso teórico sem referências concretas, porque faltaria história, e esses conceitos se articulam numa determinada história e numa determinada teoria.

Então, o que é Estado? 0 Estado é a organização política que tem domínio sobre um território e monopoliza o uso legitimo da força, essa é a definição weberiana. 0 Brasil certamente é um Estado. $O$ século XIX assiste ao surgimento dessas formações chamadas Estados-nação, entidades que emitem passaporte, que erigem e controlam fronteiras, que garantem direitos a seus cidadãos, mas às quais, ao mesmo tempo, esses cidadãos devem se identificar como filhos, devendoIhes amor e fidelidade; e que são, ao mesmo tempo, comunidades políticas e de destino.

Mas ainda me falta falar de três outros conceitos que sempre aparecem nos nossos

3 . Peter Wade (1997) tem uma explicação bastante didática sobre as diferenças entre "raça" e "etnias" que sigo, em grande parte, aqui. 
discursos. 0 primeiro deles é "classe" e, para empregá-10, peço ao meu leitor mais isenção, mais abertura, menos dogmatismo. 0 que estou pedindo? Estou pedindo o seguinte: que considere essa palavra fora de um discurso teórico especifico; que não diga, categoricamente: "a classe de alguém depende fundamentalmente do lugar que ele ocupa num modo de produção". Peço que faça de conta que está ouvindo esta palavra pela primeira vez. "Classe" pode ser um conceito analítico ou, como qualquer outro conceito, pode ser um conceito nativo. Pense numa pessoa qualquer, em si mesmo, em mim: essa pessoa diz que pertence a uma determinada classe, outros podem achar que ela está errada em sua auto-classificação; eu digo que sou de classe média, você diz: "classe média uma ova, o cara trabalha não sei quantas horas, pega no pesado, e vem dizer que é classe média". Percebemos, nesse exemplo, que estamos manipulando um conceito nativo de classe. 0 cidadão é preto, tem seu carro, tem também uma loja num shopping, aí vamos entrevistá- lo e ele diz que é trabalhador. Ficamos indignados: "esse cara é trabalhador uma ova, ele é classe média". A classe dele, para ele, o modo nativo como ele se identifica é como trabalhador, é essa a idéia de classe que ele tem. 0 exemplo que estou usando é real. Amauri de Souza (1971) descobriu que, nos anos 1960, no Rio de J aneiro, a maior parte da população negra, mesmo aquela que tinha rendimento alto, votava no partido trabalhista e se identificava como trabalhador, diferentemente dos brancos do mesmo nível social, que se identificavam como de classe média.

Podemos pensar em classe em termos analíticos e em termos nativos. Analiticamente, podemos pensar classe como uma associação ou como uma comunidade. Quando pensamos classe como uma comunidade, geralmente é uma comunidade de destino, mas às vezes também pode ser uma comunidade de origem, pode ser um discurso igual a esses sobre raças, etnias, etc. Alguns estudiosos (Thompson 1958; Pzreworski 1977; Burawoy 1979; Wright 1985), com os quais simpatizo muito, trabalham com a idéia de formação de classe, justamente para dizer que a classe, enquanto comunidade, está sempre em processo de formação ou dissolução, ela nunca é permanente; porque, para criar essa comunidade, precisa-se criar um discurso de origem ou um discurso de destino. Ou seja, construir uma comunidade de destino ou a comunidade de origem exige tempo, história, política - não é algo que se faça automaticamente.

0 penúltimo conceito que me falta é 0 mais difícil de todos - a cor. Os povos europeus se definem e foram definidos como brancos, no contato com os outros, considerados negros, amarelos, vermelhos. Estamos diante de um discurso classificatório baseado em cores. Temos que dar tratos à bola para compreender este que é o mais naturalizado de todos os discursos. E quando falo naturalizado, estou querendo dizer totalmente nativo, pois quanto mais nativo é um conceito mais ele é habitual, menos ele é exposto à critica, menos conseguimos pensar nele como uma categoria artificial, construída, mais ele parece ser um dado da natureza. É isso que quer dizer "naturalizado". Cor é um discurso desse tipo, uma categoria totalmente nativa; eu não posso falar muito dela, pois tenho que estudá-la mais um pouco. Eu poderia discorrer sobre raça; como surgiu a idéia de raça, os primeiros livros em que a palavra raça apareceu, qual o significado que tinha, etc.; existe uma enorme literatura sobre isso, mas sobre "cor" não existe. Na mais longínqua antiguidade, essa metáfora das cores já se aplicava à classificação dos seres humanos. "Cor" nunca é um conceito analítico, a não ser talvez na pintura, na estética, na fotografia; certamente na arte ele é um conceito analítico, mas nas ciências sociais ele é sempre nativo, usado para classificar pessoas nas mais diversas sociedades.

Gostaria ainda de chamar a atenção, nessa parte totalmente conceitual da minha exposição, em que estou a estabelecer diferença em cima de diferença, em que o discurso apa- 
rece destroncado - um braço pra cá, um dedo pra lá - sem corpo, sem história, sem matéria, para um último termo: cultura. Usamos esse termo "cultura" num sentido muito abstrato, mas também o usamos num sentido reificado, específico. Falamos assim numa determinada cultura étnica - a cultura italiana, a cultura negra, a cultura baiana -, falamos em culturas nacionais, em cultura brasileira e em culturas raciais.

Que significa, afinal de contas, o termo "cultura"? Isso, numa discussão como esta, é fundamental. Vamos examinar os discursos efetivos, reais, em que o termo "cultura" aparece com referência ao Brasil, à nação brasileira.

Se examinarmos o caso brasileiro, veremos de uma maneira especifica a mudança no significado do termo. A primeira coisa a lembrar é a seguinte: as raças foram, de fato, um conceito nativo no Brasil, e foram durante muito tempo uma categoria de posição social. Pelo menos até o começo do século XX, essa era uma categoria totalmente antinatural; somos uma nação que se formou com a escravidão, e essa escravidão não era uma escravidão generalizada de todos os povos, mas somente daqueles localizados numa determinada parte do continente africano. Os povos que escravizamos vieram da África ocidental e da África meridional, hoje Congo, Angola, Moçambique, Zaire e, subindo a costa ocidental, a Nigéria, o Níger e Golfo do Benin. Foram dessas regiões que vieram os povos escravizados em toda a América. Um sistema muito próprio de comercialização que envolvia negreiros da Holanda, de Portugal, do Brasil, da Inglaterra, da França, etc., alguns reinos africanos e as colônias americanas. Essas pessoas escravizadas foram chamadas de "africanas" e "negros"; essas foram, digamos, as duas identidades criadas originalmente na sociedade escravocrata brasileira, em que o negro tinha um lugar e esse lugar era a escravidão.

Então, nessa sociedade muito racialista a raça era importante, nativamente importante, para dar sentido à vida social porque alocava as pessoas em posições sociais. Essas posições sociais foram chamadas originalmente de "clas- ses". Usando Weber, que distingue os grupos abertos - como as classes - dos fechados como as castas - uma boa parte da literatura sociológica brasileira afirma que a colônia brasileira era uma sociedade de castas. Isso porque, no nosso caso, a relação social era fechada pela cor - negro -, que sinalizava seja a idéia de raça, seja a idéia de cultura e civilização, seja a idéia religiosa de uma descendência divina. As pessoas comuns, entretanto, sempre se referiram a essa divisão entre "senhores" e "escravos" como uma divisão de classes.

As raças e as classes, portanto, se articulavam intimamente, em seu sentido nativo. No entanto, ainda não conhecíamos o racismo moderno. Ao dizer isso, estou supondo que o meu leitor saiba o que seja o racismo chamado "cientifico", isto é, aquele que se justifica pela ciência. Pois bem. Muitos autores, entre eles Colette Guillaumin (1992), afirmam que o racismo e a "raça" são produtos da modernidade, ou seja, que a idéia de raça não existiria fora da modernidade. 0 que eles querem dizer com isso? Eles querem dizer que a idéia de raça, tal como a temos hoje, pressupõe uma noção chave para a ciência moderna, a de natureza imanente, da qual emana um determinado caráter, uma determinada psicologia, uma determinada capacidade intelectual. A idéia científica de que a natureza se desenvolve propulsionada por seus próprios mecanismos internos é imprescindível para essa idéia moderna de raça. Feita essa distinção, não se pode negar que a palavra "raça" é anterior a essa idéia moderna. Mas trata-se então de uma idéia não científica, inteiramente teológica, que no Brasil, nos Estados Unidos e em outros lugares justificou a escravidão.

Construiu-se para a escravidão, primeiro, uma justificativa em termos teológicos e não em termos científicos. Todos conhecem, por exemplo, o mito de que os negros são descendentes de Cã, da tribo amaldiçoada de Canaã. Realmente, muitos escravocratas e fazendeiros achavam que tinham uma missão civilizadora, que estavam redimindo os filhos de Cã, descen- 
dentes daquela tribo perdida, trazendo-os para a civilização cristã, agora, para aprender o valor do trabalho.

0 fato é que esse racialismo que marcou a sociedade e a nação brasileiras desde 0 seu início, foi cedendo lugar aos poucos a fórmulas muito mais brandas. Esse processo é razoavelmente bem estudado pela historiografia, mas não completamente desvendado. Sabe-se, por exemplo, que, no Brasil, a ordem escravocrata convivia com um número de alforrias muito grande e um tráfico muito intenso de escravos, de sorte que o que alimentou a escravidão no Brasil foi o tráfico e não a reprodução de escravos. Assim, com o tempo, se formou, no Brasil, uma classe de homens livres pretos, mulatos e pardos, que foi forçando e conquistando o seu lugar na sociedade, o que fez com que essa racionalização teológica fosse abrandada. Onde eu quero chegar é: em algum momento da história, possivelmente pressionada pelo avanço social dos ex-libertos e de seus descendentes, a categoria predominante em termos de classificação social passou a ser "cor" e não "raça". Ganhou esse estatuto de categoria nativa mais importante. Essa idéia de cor está hoje na base do que se chama de nação brasileira, desse Estado-nação. Desde a Independência, temos um projeto de nação que está ligado à construção de um Estado nacional; deixamos de ser parte do Estado português, passamos a formar um Estado brasileiro mantendo a escravidão, mas tínhamos já integrado um número grande de pretos libertos, de homens livres de cor, e a importância da cor não cessou de crescer desde então.

Dito isso, permita-me um salto histórico. Vamos pensar agora o nosso tempo moderno, dos anos 1930 pra cá. Podemos, então, distinguir três grandes períodos.

Temos uma primeira fase, de constituição da nação brasileira, e aqui eu falo de nação como comunidade de destino, na qual prevalece a idéia de cor sobre a idéia de raça. 0 anti-racialismo é uma das ideologias fundadoras dessa nação.
Quando esse discurso se cristaliza? Ele se cristaliza basicamente nos anos 1920, 1930, e encontra em Gilberto Freyre o seu principal intelectual. 0 marco pode ser 1933, ano de publicação de Casa-Grande e Senzala, mas pode ser também a Semana de Arte Moderna em 1922, pois todos os modernismos vão perseguir exatamente uma idéia nova de Brasil e de povo brasileiro.

É verdade que temos antecedentes desde o Império. 0 primeiro foi, sem dúvida, 0 movimento romântico brasileiro, 0 indianismo. 0 primeiro momento de uma nação independente, da nação brasileira. Fomos buscar no índio o símbolo da nação. Essa foi uma maneira de deixar de ser europeu e passar a ser brasileiro. Essa primeira construção nacional foi tão marcante que, na minha terra, Bahia, até hoje, os negros, e o povo em geral, se identificam com o caboclo do Dois de Julho.

Vale aqui mais um parêntese. Quando foi proclamada a Independência brasileira as tropas portuguesas de Salvador não se renderam. Ao contrário, alimentaram o projeto de manter Salvador como um porto português, um enclave; dando ensejo a uma luta pela Independência que durou mais ou menos um ano, até que, finalmente, em 2 de julho de 1823, as tropas brasileiras entraram em Salvador, pela estrada da Liberdade. Ali, na Lapinha, se construiu uma Casa dos Caboclos, porque os caboclos foram lutar na guerra da Independência. Toda essa construção simbólica é feita no Império e perdura até hoje. Vejam-se os candomblés de caboclos, eles espelham essa idéia de nacionalidade que vem desse movimento de indianismo (Santos, 1995). Ultimamente, quem melhor tem estudado esse período, esta construção simbólica, tem sido Lilia Schwarcz (1999) e José Murilo de Carvalho (1991), cuja leitura recomendo.

Silvio Romero e a chamada "geração realista" vêm logo depois. Essa geração vai enfrentar o problema nacional fundamental, qual seja: não temos mais escravos e agora não podemos mais fazer de conta que o negro li- 
vre é caboclo, que o negro livre é índio. Vai ser preciso incorporar agora esse povo, essa raça, nessa nação nova, criar símbolos nacionais. Foi isso que a geração de $1920 \mathrm{fez}$, num período muito fértil da nacionalidade, da qual participaram todos, inclusive os movimentos negros da época. Até hoje é impossível pensar o movimento negro sem pensar que ele continua lutando para ser integrado a essa nação, ainda que, agora, de uma forma que não seja simplesmente simbólica. Pois, simbolicamente, os negros foram incorporados sim, por Freyre (1933), por Mário de Andrade (1944), pelos folcloristas, pelos modernistas. Nos anos 1950, a palavra de ordem que encontramos ainda era a seguinte: a cor é apenas um acidente. Somos todos brasileiros e por um acidente temos diferentes cores; cor não é uma coisa importante; "raça", então, nem se fala, esta não existe, quem fala em raça é racista.

$\mathrm{Na}$ sociologia acadêmica, o movimento interpretativo da realidade racial que se constitui no pós- 1930 começou com o trabalho de campo de Donald Pierson, na Bahia, em 1939, e segue até o final dos estudos da Unesco sobre relações raciais. Nesse período, se formam duas interpretações. A primeira, que foi capitaneada pelo mesmo Donald Pierson (1971), diz o seguinte: a sociedade brasileira é uma sociedade multirracial de classes. 0 que ele quer dizer com isso é que se trata de uma sociedade na qual as "raças" não eram propriamente "raças", mas grupos abertos. Ou seja, a raça não seria um principio classificatório nativo (ninguém teria raça nativamente, mas sim cor); nem seria também um grupo de descendência. 0 modo de classificação por cor não fecha as portas para ninguém, não pesa quase nada nas oportunidades sociais, a sociedade seria uma sociedade de classes, uma sociedade aberta, em que negros, brancos, índios, mestiços, pessoas de qualquer cor, podem transitar pelos diferentes grupos sociais. Ficamos pensando se isso era uma construção ideal, ou se pretendia ser uma representação do real, porque sabemos por monografias, por etnografias, que certos clubes eram fechados, que certos lugares das praças públicas das cidades eram vedados aos negros, etc. Mas, o mais importante para nós é que Pierson inaugura uma outra retórica de raça, em que a palavra "classes", já de domínio popular, ganha um sentido acadêmico, weberiano, sendo depois popularizada com esse novo sentido.

Como é possível notar, a primeira maneira das ciências sociais pensarem essa realidade continuou colada à ideologia nacional. É difícil perceber onde acaba a ciência e onde começa a vontade de nação. É como se a ideologia nacional, que move as relações sociais, passasse a ser o discurso da ciência, apresentando-se como análise. Trata-se de um discurso nativo ou de um discurso analítico?

Um segundo período é marcado pelos estudos patrocinados pela Unesco, principalmente os realizados no Rio e em São Paulo (Maio, 1997). Esses estudos documentam pela primeira vez, de maneira racional e científica (ou seja, utilizando-se das técnicas de observação desenvolvidas pela sociologia e pela antropologia social), a situação do negro no Sudeste do Brasil. Seria a "raça" uma forma de classificação social no Brasil? Pensava-se comumente que "a cor era apenas um acidente", éramos todos brasileiros. Esse pensamento era atribuído ao povo, ou seja, não apenas os ideólogos, mas as pessoas comuns, do povo, brancos e negros, pensariam assim. Os estudos de Bastide e Florestan (1955) e Costa Pinto (1953) rompem radicalmente com essa forma de pensar. A grande discussão que eles estabelecem é uma discussão já colocada pelo movimento negro nos anos 1930: a existência do preconceito racial no Brasil, apesar do ideal de democracia racial. 0 que é preconceito? Definia-se preconceito, geralmente, a partir da experiência americana de preconceito - ponto de vista que pode ser aprofundado pela consulta a Blumer $(1939,1958)$. A idéia básica de Blumer é que o preconceito existe como uma reação emocional de um grupo racial (o branco) que se sente ameaçado por outro (o negro) na competição por recursos em uma ordem igualitária (democrática). 
0 que Pierson dizia é que o preconceito, assim definido, não existia no Brasil. Haveria, sim, casos individuais de preconceito, casos isolados, mas não como fenômeno social; ou seja, os brancos, enquanto grupo, no Brasil, não cultivariam o medo de serem deslocados pelos negros. Em Marvin Harris (1956), que segue a orientação de Blumer, o argumento se estende ao limite, pois ele diz que, no Brasil, a classe dominante, a branca, nunca precisou sacar a carta racial do colete, ou seja, os negros nunca ameaçaram, e os brancos nunca precisaram sentir medo, e portanto nunca desenvolveram preconceito. 0 fato é que, nesses anos, a grande discussão era: existe ou não existe preconceito racial no Brasil?

A chamada "escola paulista de sociologia" começou a desenvolver um tipo de argumentação diferente, mais ou menos assim: existem áreas tradicionais, como a Bahia, Pernambuco, onde isso pode ser verdade, onde não existiria preconceito porque não haveria ordem competitiva, igualitária. Mas, nas áreas de desenvolvimento capitalista, em São Paulo, onde se organiza uma sociedade de classes, à medida que aumenta a competição social, aparece o preconceito, ou seja, a ameaça do negro tomar o lugar do branco torna-se real. Em contraposição, os críticos da escola paulista interpretavam tal preconceito como cultura de importação, nutrida principalmente por certos grupos imigrantes pouco adaptados ainda à vida nacional. A escola paulista, ao contrário, buscava explicações estruturais, ou seja, remetia-se à estrutura social em mutação - o capitalismo industrial, em gestação no país, estaria também deslanchando o fenômeno do preconceito racial.

0 fato é que essa escola cunhou a idéia do mito da democracia racial. Aquela sociedade multirracial de classes, de que falava Pierson em 1940, se transformou, com o tempo, numa coisa chamada democracia racial, cujas origens estão na idéia de Freyre de que a cultura lusobrasileira, o "mundo que o português criou", teria desenvolvido uma "democracia social" mais profunda e pujante que a "democracia política" dos anglo-saxões e franceses. Essa democracia social seria basicamente um modo diferente de colonizar que significou miscigenar-se, igualar-se, integrar os culturalmente inferiores, absorver sua cultura, dar-lhes chances reais de mobilidade social no mundo branco. Freyre fala depois em "democracia étnica" para dizer que, no Brasil, apesar de uma estrutura política muito aristocrática, desenvolve-se, no plano das relações raciais, relações democráticas. São essas idéias que foram traduzidas como "democracia racial" e ganharam, por um bom tempo, pelo menos dos anos 1940 até os 1960 , a conotação de um ideal político de convivência igualitária entre brancos e negros (Guimarães, 2002).

Quando o Florestan Fernandes (1965) fala em mito da democracia racial, ele estava querendo dizer o seguinte: essa democracia racial seria apenas um discurso de dominação política, não expressava mais nem um ideal, nem algo que existisse efetivamente, seria usado apenas para desmobilizar a comunidade negra; como um discurso de dominação, seria puramente simbólico, sua outra face seria justamente o preconceito racial e a discriminação sistemática dos negros.

0 termo "democracia racial" passa, portanto, a carregar e sintetizar uma certa constelação de significados. Nela, raças não existem e a cor é um acidente, algo totalmente natural, mas não importante, pois o que prevalece é o Brasil como Estado e como nação; um Brasil em que praticamente não existem etnias, salvo alguns quistos de imigrantes estrangeiros. Inventa-se, portanto, um povo para o Brasil, que passa a ter samba, passa a ter um pouco da cultura negra, que até aqui não existia pois se, no Império, predominou a mística do índio, e na República a mística do imigrante europeu, somente na Segunda Republica o negro vai dar coloração à nação, à idéia de uma nação mestiça.

Apenas a partir de 1978, surgirá um ator político, o Movimento Negro Unificado, a golpear esse discurso nacional de maneira mais contundente. Ainda que a crítica da "democracia racial", o denunciá-la como mito, date de 1964, a repressão política impediu qualquer reação organizada. 
Por que o MNU irá golpear de forma tão contundente a "democracia racial"? Porque ele vai reintroduzir a idéia de raça, vai reivindicar a origem africana para identificar os negros. Começase a falar de antepassados, de ancestrais, e os negros que não cultivam essa origem africana seriam alienados, pessoas que desconheceriam suas origens, que não saberiam seu valor, que viveriam 0 mito da democracia racial. Para 0 MNU, um negro, para ser cidadão, precisa, antes de tudo, reinventar sua raça. A idéia de raça passa a ser parte do discurso corrente, aceito e absorvido de certo modo pela sociedade brasileira, o que não se explica senão pelas mudanças que ocorreram também na cena internacional, que tornaram esse discurso bastante poderoso internamente. Mas o fato é que se introduz de novo a idéia de raça no discurso sobre a nacionalidade brasileira.

$\mathrm{Na}$ sociologia acontece, paralela e independentemente, algo parecido. Carlos Hasenbalg (1979) e Nelson do Valle e Silva (1980) simplesmente analisam os dados agregados, produzidos pelo IBGE, e demonstram por a mais $b$ que as desigualdades econômicas e sociais entre brancos e negros, ou seja, entre aqueles que se definem como brancos e como pretos e pardos (negros, na definição do ativismo negro), não podem ser explicadas nem pela herança do passado escravagista, nem podem ser explicadas pela pertença de negros e brancos a classes sociais distintas, mas que tais desigualdades resultam inequivocamente de diferenças de oportunidades de vida e de formas de tratamento peculiares a esses grupos raciais.

Uma enorme coincidência estatística fez com que Carlos e Nelson reforçassem ainda mais o discurso do Movimento Negro, que naquele momento procurava dividir a população brasileira em brancos e negros, recusando os termos, oficiais ou não, que classificavam os mestiços em morenos, pardos, escuros, etc. Sabemos que os dados do IBGE trazem cinco categorias - brancos, pretos, pardos, amarelos e indígenas. A categoria "preto" é diminuta; a proporção, no Brasil, dos que se declaram pre- tos nunca passou contemporaneamente de $5 \%$. Ora, isso representava uma grande dificuldade para a análise desagregada dos dados, pois não permitia que se fizessem testes estatísticos robustos. Por outro lado, no total, a categoria parda, mais numerosa, não apresentava grandes diferenças em relação à preta em termos de situação, medida por uma série de indicadores. Como seria estatisticamente recomendável agregar os dados, Nelson e Carlos juntaram os pretos aos pardos, ou seja, fizeram, analiticamente, o que o movimento negro fazia na política, chamando o agregado resultante de "negros". Assim o termo "negro" para significar afro-descendente ganhou credibilidade nas ciências sociais, assim como o discurso da desigualdade racial, também a partir das ciências sociais, contagiou o discurso político.

Bom, aí a confusão está formada; e por quê? Porque agora tem-se um conceito que não era nem analítico nem nativo. Não era analítico porque a sociologia não o sustentava, tampouco a biologia, e não era nativo senão para uma parte mínima da população brasileira, ou seja, para os ativistas e simpatizantes do MNU. O que eu escrevi em "Racismo e Antiracismo no Brasil" tenta desenrolar esse nó, do ponto de vista teórico, propondo um conceito sociológico de raça (Guimarães, 1999).

Que conceito é esse? Parto da crítica à categoria "cor", pois a análise dessa categoria, no Brasil, nos leva à conclusão, sem grande dificuldade, de que a classificação por cor é orientada pela idéia de raça, ou seja, que a classificação das pessoas por cor é orientada por um discurso sobre qualidades, atitudes e essências transmitidas por sangue, que remontam a uma origem ancestral comum numa das "subespécies humanas". Isso não foi muito difícil pois pude me restringir a resenhar criticamente os antropólogos dos anos 1940, 1950 e 1960, que documentaram ricamente tal fato. 0 meu argumento é o seguinte: "cor" não é uma categoria objetiva, cor é uma categoria racial, pois quando se classificam as pessoas como negros, mulatos ou pardos é a idéia de raça que 
orienta essa forma de classificação. Se pensarmos em "raça" como uma categoria que expressa um modo de classificação baseado na idéia de raça, podemos afirmar que estamos tratando de um conceito sociológico, certamente não realista, no sentido ontológico, pois não reflete algo existente no mundo real, mas um conceito analítico nominalista, no sentido de que se refere a algo que orienta e ordena o discurso sobre a vida social.

Temos outros dois complicadores adicionais.

Primeiro, houve um movimento de reação à vontade do MNU de desmistificar a democracia racial, à sua ânsia de culpar o preconceito e a discriminação raciais como responsáveis, pelo menos em parte, pela desigualdade racial no Brasil; junto com isso houve também, nos anos 1980 e 1990, um grande abalo no nosso sentimento de nacionalidade, resultado de sucessivas crises econômicas e políticas houve crises de governabilidade e ameaças de desintegração nacional, com o surgimento de movimentos separatistas.

Segundo, houve, no plano da academia, uma certa reação à tentativa de demonização de Gilberto Freyre. Surgiu na academia um movimento de reinterpretação da democracia racial como um mito. Formou-se uma certa matriz interpretativa, que diz assim: "Tudo bem, a democracia racial é um mito, mas vocês, sociólogos, não entendem muito de mito, não. Mito não é só falsa ideologia, mito é uma coisa mais importante do que o que vocês acham; mito, na verdade, é um discurso sobre a origem das coisas, um discurso sobre 0 dia-a-dia, que não precisa ser real, ao contrário, é efetivo apenas na medida em que orienta a ação das pessoas, em que dá sentido às relações sociais do dia-a-dia. Nesse sentido, o mito da democracia racial é e continuará sendo muito importante para a idéia de nação brasileira".

Esse é um argumento muito forte, pois significa dizer o seguinte: "Apesar da militância do $\mathrm{MNU}$, qualquer um que saia à rua e converse com as pessoas vê que a democracia racial está viva, enquanto mito".
Recentemente eu comecei a reagir a esse discurso (Guimarães, 2002), pensando 0 seguinte: esse argumento é muito bom porque nos ensina a pensar as relações sociais, tais como elas se dão no cotidiano; nesse sentido, ele põe fim à politização excessiva do tema. $M$ as ele tem um defeito - ele acaba se apegando muito à idéia de estrutura, de longa duração, torna-se quase que um discurso a-histórico, como se estivéssemos tratando com uma matriz que não teve inicio e não terá fim. Se os que usam tal argumento são pouco críticos a respeito da historicidade dessa matriz, então eu os fustigo, perguntando: como nasceu a democracia racial? Quando se transformou num compromisso político? Será que esse discurso não pode acabar? Será que não está acabando? E, inspirado nas idéias de alguns cientistas políticos, como Amaury de Souza (1971), por exemplo, penso a democracia racial como um compromisso político, que teve um começo, conheceu o apogeu, passou por crises e, talvez, tenha se esgotado.

Uma observação final de cunho metodológico. Tratei até aqui de termos analíticos, de termos nativos, agora gostaria de tratar de termos de pesquisa. Como é que se observam "raças" ou como se observa a "cor" de uma pessoa? Temos esses dois momentos na pesquisa: num primeiro, temos nossas hipóteses, nossas categorias analíticas, nossas categorias nativas; num segundo momento, precisamos transformar "cor" ou "raça" em algo que possa ser observado, quantificado, analisado. A primeira regra, para quem faz pesquisa, é que é necessário se ter domínio da linguagem nativa, pois se as questões teóricas do pesquisador não puderem ser traduzidas em questões que utilizem a linguagem nativa, tais perguntas não serão entendidas. Precisamos, pois, trabalhar com 0 senso comum, traduzir conceitos analíticos em categorias nativas; temos que frasear a pergunta de modo a obter uma resposta sobre o que queremos. No nosso caso, estamos querendo saber como uma pessoa se classifica em termos raciais no Brasil. Como perguntar? 
Segundo a etnografia que se faz no Brasil, o conceito de raça continua a não ser conceito nativo, ainda que comece a ser adotado por vários grupos sociais, não é um termo usual e de sentido inequívoco. A melhor maneira de se perguntar quando se quer classificar em termos raciais, portanto, continua a ser: "qual é a sua cor?" ou "como o sr(a). se classificaria em termos de cor?" ou variações em torno da pergunta sobre cor. 0 grande problema é que cada vez mais essa pergunta acaba dando resultados inesperados. No passado, a boa pergunta para se observar a identidade racial era perguntar sobre a cor, mas com toda essa luta ideológica em torno da racialização, cada vez mais, começa a aparecer ruído nas respostas a essa pergunta. 0 que fazer? Substituir a palavra "cor" por "raça"? Mas, será que a maioria das pessoas aceita e entende a pergunta? Ou será que vai reagir à idéia de raça como reagia antigamente? Tem-se aqui um problema. No estágio em que estamos atualmente, o tema se tornou tão pouco confiável em termos de operacionalização que os pesquisadores precisam fazer duas ou três perguntas. Uma maneira clara de classificar, embora seja conceitualmente pouco sociológica, é aquela feita pelo entrevistador. Simplesmente, pede-se que a pessoa que está entrevistando classifique o entrevistado em termo de cor. Essa é uma possibilidade. 0 problema dessa forma de classificação é que desse modo se obtém uma identidade atribuída por outrem. Do ponto de vista da teoria sociológica, não parece ser uma boa solução, porque se trata de medir uma variável que, na verdade, é uma forma de identidade subjetiva do individuo; então, atribuir identidade é complicado, mas, às vezes, é a única maneira disponível. Eu já fiz isso, não quando me deparei com pessoas que eu entrevistava, mas com fichas de registro funcional de pessoas. Nesse caso, eu tive que classificar racialmente a partir da percepção gerada por uma fotografia. Procurei usar muitas categorias para que depois fosse possível agregá-las de acordo com os resultados estatísticos que eu obtivesse. Usei, por exemplo, uma categoria inexistente no censo, "moreno", que é o "branco" escuro, muito usado no Nordeste e no litoral, onde o queimado de sol é muito valorizado, junto como a categoria "mulato", tipo mais negróide, ainda que mais claro que o "preto". Essas categorias se revelaram facilmente traduzíveis em termos das categorias censitárias, posto que grande parte dos "morenos" são brancos sociais.

Por outro lado, o DataFolha (Folha de S. Paulo, 1995), assim como outros pesquisadores, já utilizaram simultaneamente três diferentes formas de classificação. Primeira forma: as categorias do IBGE são usadas para que o entrevistador classifique sem perguntar; segunda forma: faz-se uma pergunta aberta "Qual é a sua cor?"; terceira forma: repete-se a pergunta censitária, uma pergunta fechada com cinco alternativas - branco, preto, pardo, amarelo e indígena. Por que fazer uma pergunta aberta? Marvin Harris (1993), um dos antropólogos que melhor conhece o sistema de classificação racial no Brasil, pois tem estudado o assunto desde os anos 1960, quando era estudante de pós-graduação em Columbia, escreveu recentemente uma série de artigos irados contra as categorias do IBGE, dizendo que o IBGE estava perpetuando uma violência com a identidade das pessoas no Brasil, pois estas se consideravam morenas e não pardas; argumentou, ademais, que essa categoria, "parda", não existia na vida cotidiana brasileira. Harris forçou, assim, que se retomassem os estudos de classificação racial no Brasil. Deve-se tomar o cuidado, portanto, sempre que possível, de se fazer uma pergunta aberta, deixar a pessoa falar o que quiser e anotar, posto que não há hoje em dia consenso sobre que categorias são usadas nativamente. Finalmente manter a forma de classificar do IBGE, sempre fraseada com a palavra "cor", faz-se necessário para manter-se a comparabilidade entre diversas fontes de dados. Quando, ao contrário, se está lidando com um grupo específico, cujas categorias de classificação racial são conhecidas, deve-se empregar essas categorias. Foi o que aconteceu 
com J oão Batista Felix (2002), quando entrevistou militantes e perguntou: "qual é a sua raça?". Esses militantes tinham uma teoria racial muito consistente sobre o mundo e sobre si mesmos, em que a idéia de raça em termos políticos era central e na qual a idéia de cor, que é a idéia normal dos brasileiros, continuava vigendo. Ou seja, essas pessoas fundiram uma classificação brasileira com uma classificação militante, na qual a "raça" referia-se a uma ascendência biológica e posição política, enquanto a cor a uma tonalidade de pele considerada objetiva. Até que ponto esse discurso racial vai se espraiar, vai ganhar adeptos fora do movimento? Outro exemplo, no nosso Censo Étnico-Racial da USP (Guimarães; Prandi, 2002), perguntamos: "Você é descendente de imigrantes estrangeiros?". É uma pergunta à qual, se feita algum tempo atrás, na minha terra, todo mundo responderia "não". Aqui, em São Paulo, agora, em 2000, eu não sei qual será o resultado, pois estamos vivendo um tempo em que as pessoas começam a cultivar diferenças, identidades, origens. É provável que apareçam muitos descendentes de portugueses, muito mais do que seria lógico esperar em São Paulo, simplesmente porque os brasileiros brancos, sem nenhum ancestral português conhecido, tenham passado a reivindicar essa ascendência esquecida. 0 que eu estou tentando defender é que qualquer categoria só faz sentido no interior de um discurso, no nosso caso, racial; quando nos deparamos com uma resposta sobre identidade, temos que investigar qual o discurso que está orientando as respostas.

\section{Referências bibliográ fic as}

ANDRADE, Mário. Macunaíma. São Paulo: Livraria Martins, 1994.

APPIAH, Kwame A. Na casa de meu pai. Rio de J aneiro: Contraponto, 1997.

BASTIDE, R.; FERNANDES, F. Relações raciais entre negros e brancos em São Paulo. São Paulo: Anhembi, 1995.

BOAS, Franz. Race, language and culture. Nova York: The Macmillan Company, 1940.

BLUMER, Herbert. The nature of racial prejudice. Social Process in Hawaii, Honolulu, v.5, p.11-20, 1939.

. Race prejudice as a sense of group position. Pacific Sociological Review, v.1, p. 3-8, Spring 1958.

BURAWOY, Michael. Manufacturing consent. Chicago: University of Chicago Press, 1979.

CARVALHO, J osé Murillo. Bestializados: o Rio de J aneiro e a República que não foi. São Paulo: Companhia das Letras, 1991.

DURKHEIM, Emile. As regras do método sociológico. São Paulo: Ed. Nacional, 1970.

FÉLIX, J oão Batista de J. Chic Show e Zimbabwe e a construção da identidade nos bailes black paulistanos. 2000. Dissertação (Mestrado) - Faculdade de Filosofia Letras e Ciências Humanas da Universidade de São Paulo, São Paulo, 2000.

FERNANDES, Florestan. A integração do negro na sociedade de classes. São Paulo: Ed. Nacional, 1965.

FREYRE, Gilberto. Casa-grande \& senzala: formação da família brasileira sob o regime da economia patriarcal. Rio de J aneiro: Schimidt, 1933.

GUILLAUMIN, Colette. Sexe, race et pratique du pouvoir: l'idée de nature. Paris: Côté-femmes, 1992.

GUIMARÃES, Antonio Sérgio A. Racismo e anti-racismo no Brasil. São Paulo: Editora 34, 1999. . Classes, raças e democracia. São Paulo: Editora 34, 2002. 
; PRANDI, Reginaldo. Relatório Substantivo. In: Censo Étnico-Racial da Unversidade de São Paulo, 1. Relatório de Pesquisa. São Paulo: FFLCH-USP, 2002.

HARRIS, Marvin. Race and class. In: . Town andcCountry in Brazil. New York: Columbia University Press, 1956.

. et al. "Who are the whites? Imposed census categories and the racial demography of Brazil". Social Forces, Chapel Hill, V. 72, n. 2, p. 451-462, dez. 1993.

HASENBALG, Carlos A. Discriminação e desigualdades raciais no Brasil. Rio de J aneiro: Graal, 1979.

HASENBALG, Carlos A.;SILVA, N. V. Relações raciais no Brasil contemporâneo. Rio de J aneiro: Rio Fundo Editora, 1992.

LIMA, Vivaldo da C. A Família-de-Santo nos Candomblés J eje-Nagôs da Bahia. 1971. Dissertação (Mestrado em Ciências Sociais). Salvador; 1971.

MAIO, Marcos Chor. A história do Projeto Unesco: estudos raciais e ciências sociais no Brasil. 1997. Tese (Doutorado) - IUPERJ, Rio de J aneiro, 1997.

MARX, Karl. Para a crítica da economia política. São Paulo: Abril, 1974. (Os pensadores, v. 35).

PIERSON, Donald. Brancos e pretos na Bahia (estudo de contacto racial). São Paulo: Editora Nacional, 1971.

PINTO, Luis Aguiar C. O negro no Rio de J aneiro: relações de raças numa sociedade em mudança. São Paulo: Ed. Nacional, 1953.

PRZEWORSKI, Adam. From proletariat into class: the process of class formation from Karl Kaustki's 'The class struggle' to recent debates. Politics and Society, v. 7, p. 4, 1977.

RACISMO CORDIAL. Folha de S. Paulo, São Paulo, 1995.

SANTOS, J océlio Teles dos. 0 dono da terra: 0 caboclo nos Candomblés da Bahia. Salvador: Sarah Letras, 1995.

SCHWARCZ, L. Moritz. As barbas do imperador. São Paulo: Companhia das Letras, 1999.

SILVA, Nelson do Valle. 0 preço da cor: diferenciais raciais na distribuição de renda no Brasil. Pesquisa e Planejamento Econômico, Rio de J aneiro, v. 10, n. 1, p21-44, 1980.

SOUZA, Amauri de. Raça e política no Brasil urbano. Revista de Administração de Empresas, Rio de J aneiro, v.11, out./dez. 1971.

THOMPSON, E.P. The making of english working class. London: Vintage, 1958.

WADE, Peter. Race and ethnicity in Latin America. London: Pluto Press, 1997.

WAGLEY, Charles. Races et classes dans le Brésil rural. Paris: UNESCO, 1952.

WEBER, Max. Sobre a teoria das ciências sociais. São Paulo: Martins Fontes, 1970.

WRIGHT, E. O. Classes. London: Verso, 1985.

Recebido em 22.05.03

Aprovado em 13.06 .03

Antonio Sérgio Alfredo Guimarães é professor do Departamento de Sociologia da USP. É doutor pela University of Wisconsin-Madison e livre-docente em sociologia política. Publicou sobre o tema deste artigo: Preconceito e discriminação (Salvador: Novos Toques, 1998); Racismo e anti-racismo no Brasil (São Paulo: Ed. 34, 1999) e Classes, raças e democracia (São Paulo: Ed. 34, 2001), além de artigos e coletâneas. 